\title{
An Analysis of Spoken Language and Written Language and How They Affect English Language Learning and Teaching
}

\author{
Bei Zhang \\ School of Foreign Studies of Shandong University of Finance and Economics, Jinan, China
}

\begin{abstract}
Language plays a crucial role in the development of human society. It is the main means of communication between individuals, groups and countries. Nowadays in China, more and more people are learning English as a second language. What is the effective method of learning a foreign language becomes their chief concern. Basically speaking, four modules are involved in the process of second language acquisition. They are listening, reading, writing and speaking. In English language teaching and learning, mastering these four modules means a lot. Speaking and writing skills, as the productive modules, are usually more difficult for learners. In this essay, from the origin and functions of language, the correlation and disparities between speaking and writing skills are analyzed and possible ways of improving these two skills in second language acquisition are explored and suggested.
\end{abstract}

Index Terms — second language acquisition, writing, speaking, communication

\section{INTRODUCTION}

Kachru and Nelson suggest that English has developed from the native language of a relatively small island nation to the most widely taught, read, and spoken language that the world has ever known (2001, p. 9 cited in Kuo, 2006, p. 213). China, one of the leading emerging economies with the world's largest population, perhaps enjoys the largest population of ESL learners. With the proceeding and advancing of globalisation, English learning and teaching attracts more and more attention in China. Meanwhile, improving English proficiency becomes a significant topic.

As for English proficiency, there are generally four basic skills involved in the language learning process. They are listening, reading, writing and speaking. Listening and reading are the processes of receiving, whereas, writing and speaking are processes of production, or put it another way, output.

In the case of first language acquisition, from traditional Chinese idea, the first thing to do should be listening, and then speaking and reading, writing usually comes the last. From my point of view, these four skills cannot be divided so clearly and they are interweaved with each other in the process of language acquisition. But the rough sequence is like this. Perhaps it is because of the different degrees of difficulty of these four skills. Generally speaking, receiving is more easier than producing and verbal process is easier than written things. However, in the case of second language learning, this sequence does not always work the same way.

In China, we usually start to learn a foreign language at the age of around 6 years old. This foreign language is often the English language. The general sequence of the four skills learning is: reading, listening, writing and speaking. This shows that writing and speaking, the productive skills, are comparably difficult for English language Learners. Whereas, in the practical learning process, these four skills work together and help each other to improve. For example, when you are listening to the target language, this also helps to develop speaking skills. Furthermore, reading does the same to writing skills.

In this essay, I will try to analyze the correlation and disparities between spoken language and written language to see how to apply them better in English language learning and teaching in China.

\section{The Characteristics AND IMPORTANCE OF ENGLISH SPEAKING AND Writing SKILLS}

When discussing the origins of language, Yule mentions two functions of language:

“...All this noise-making and gesturing, seems to be characteristic of only one of the major functions of language use, which we may describe as the interactional function. It has to do with how humans use language to interact with each other, socially or emotionally; how they indicate friendliness, co-operate or hostility, or annoyance, pain, or pleasure.

But there is another major function of language, the transactional function, whereby humans use their linguistic abilities to communicate knowledge, skills and information. ..." (1996, p. 6).

In this paragraph, Yule points out the interactional function and transactional function of language. These two functions have a commonness: communication between human beings.

Languages originated from the need for communication between and among people. From this 'need', spoken language appeared and developed, and then the written language, which catered for the need of recording and 
preserving things. To put it simply, the purpose and the function of language is to know about other people and let others know about you. Listening and reading are processes for the former and speaking and writing accomplish the task of the latter. To learn a foreign language, it is necessary to master all of these four skills. It is incorrect to suppose that you can listen to others and read materials in the target language but cannot speak and write in it at all. Language is a tool of communication of human society. This kind of communication is a bi-directional process which includes both receiving information as well as giving out information. This giving-out includes speaking and writing. In a long period, writing capability is considered to be the symbol of the well-educated. In some sense, we can say that writing skills are more advanced than speaking skills. In the case of first language acquisition, speaking is learned unconsciously in daily life and writing is learned consciously, usually in schools. But in the second language learning situation, speaking is of no easier than writing. There are various reasons for the characteristics and differences of these two skills. Here I would like to state two of them.

The first one is the learning environment. For writing, it is usually not so difficult to obtain and refer to written materials. But speaking is a skill which demands more practice in daily life. In China, English language is not used widely. Except for some loanwords from English, we seldom use English in our daily lives. For an English language learner, the English class is almost the only language environment for him/her to learn and practice English. But the classroom is only an artificial language environment. Chinese English language learners lack favourable conditions for language acquisition.

Another difficulty for learning English speaking skills regards grammar.

“...There is, to begin with, no influential description of spoken English which has, say, the status of grammars of written English. Spoken English appears very variable, and is very different from one dialect area to another. Even between speakers who mostly speak 'standard English' there is different emphasis in their selection from forms in standard English. ..." (Brown, 1983, p. 3)

Grammar offers a set of rules for language, according to which we can comprehend and produce correct language alternatives. For English writing, there are plenty of rules for us to abide by. Whereas, we could hardly find specialized grammar for speaking skills. Sometimes, Chinese English language learners speak according to the rules of writing. But speaking is not just uttering the exact written language. Another point is that native speech varies from area to area, from culture to culture, between different age groups, different levels of education, from different social classes etc. What and How should we teach spoken English? It is an issue which has been discussed by scholars for years and is still subject to debate, since spoken language is both inconstant and changeable.

\section{Correlation AND Disparities Between Spoken Language AND WritTEn Language}

In one sense, we can say that written language is the written form of what people speak. The difference between them is that one is oral and one is written. But the case is not so simple. These two forms of language perform different functions in human society and the different functions determine their fundamental differences.

Although both of them are processes of production, written language is not just spoken language written down and spoken language is not the written language read aloud. It is usual practice that people use different words and sentence structures to express the same thing in writing and speaking. Take the read-aloud case for example:

"Of course if you have actually tried to 'speak like a book' yourself, you may agree that it can be hard work. It is hard work reading aloud from a book. This may be because it is not something we are used to; or because the sentences can be awkward to read aloud - too long, too complex, or too technical. It can be tricky to get the correct intonation, and you may find you often have to re-read bits to make them sound right. Reading aloud tends to require considerable attention." (Bygate, 1991, p. 10)

When I am in junior middle school, in the English class, it is common practice to read some certain text aloud. This is a case of speaking written language. From some Chinese English teachers' point of view, reading the text aloud can help students to get a more profound impression about it and practice their pronunciation and intonation. But the language which is spoken out is far away from everyday spoken language.

The following statements summarize some of the differences between these two forms of language skills:

1) Written language tends to use longer and more complex sentences and the sentence of spoken language is shorter and easier to understand.

2) Written language usually allows for a second thought but spoken language is often produced on the spur of the moment.

3) Written language usually lasts longer and spoken language is comparably transient, except in the case of audio recordings.

4) Written language usually tends to transmit information. However, spoken language tends to express more emotions and personal feelings, perform more functions in smoothing interpersonal relations.

These points are only a small part of their differences.

Since written language and spoken language are different in so many ways, we recognize that we should follow different procedures for dealing with them in English language learning and teaching.

\section{How to Deal with Spoken Language in English Language Learning AND Teaching}


When I was a middle school student, teachers put more attention on reading and writing and provide less practice with listening and speaking. Consequently, listening and speaking skills are always my weakness in English. It is a wide-spread problem for English language learners of my age in China. To sum up the reasons:

1) The national syllabus for English language teaching places more emphasis on reading and writing than on listening and speaking.

2) The teaching conditions and teachers' proficiency are limited with regard to listening and speaking skills.

3) Listening and speaking skills are not basic requirements for assessment.

4) The social environment does not demand much for English listening and speaking skills.

However, things have changed considerably in recent years. With reference to the above,

1) The national syllabus has changed gradually to emphasize all of the four skills of English language learning, and the teaching materials have been greatly improved for this purpose.

2) The teaching conditions have been improved and some of Chinese schools now have specialized language laboratories. And some of the schools have engaged more native English language speakers to teach spoken English.

3) As regards assessment procedures, listening and speaking are given equal emphasis as reading and writing skills and a relatively complete English language assessment system has been implemented. As assessment has a backwash for learning and teaching. That is, what is assessed determines what is taught and learned. Teachers and students must work hard to improve listening and speaking skills to satisfy the assessment.

4) In recent years, the English language has been used much more widely in China. For example, more and more foreign companies whose official language is English have entered Chinese market. If a student wants to work for the foreign companies, a good English speaking proficiency would provide him/her a better opportunity.

In addition, here I would like to put forward two international tests for English language to illustrate this change. About 2 decades ago, TOEFL was very popular in China and it occupied a dominant status for English language test. When IELTS came up, it gradually becomes more and more popular as a significant test indicating learner's English language level. The big difference between these two forms of test is that IELTS put more emphasis on assessing learner's practical capability in using the spoken language. If the learner wants to get a satisfactory result in IELTS test, he/she must work hard to obtain a good English spoken skill.

All these changes have had fundamental effects on English language learning and teaching in China. Teachers and learners pay much more attention to practical usages of English language, especially the learning of spoken language. How to learn and how to teach spoken language are attracting more and more attention.

At the very mention of spoken language, what comes first to my mind is that related to pronunciation and intonation. Undoubtedly, they are two of the basic elements for speaking a language. For a beginner, it is not surprising that he/she spends a considerable time on repeating some certain vowels or consonants and on trying to distinguish between similar sounds. The exactness of pronunciation is really of great importance. I have heard a story from my friend. When he was in London waiting for the coach to Bath, he wanted to confirm if that bus stop was the very stop for his coach and asked a man standing beside. Unfortunately, great confusion occurred between them concentrating on the words 'Bath' and 'bus'. That man kept saying, 'yes, this is the bus stop' in reply to his enquiry. This is a problem of the similar pronunciation of 'th' and's'. This story shows us how important the right pronunciation is. It really affects our daily lives greatly.

In China, spoken English is usually taught and learnt in these ways: model dialogues, pattern practice, oral drill tables, look-and-say exercises, oral composition, etc. Sometimes we have group discussion and, very occasionally, we hold debates on particular issues for the purpose of practicing spoken English.

However, this is far away from enough. Spoken language is such complex a system and the learners must learn much more things besides these.

How is spoken language produced? Is it to read the written language aloud together with some oral expressions? Or it is another completely different language system? These are difficult questions to answer. Here I would like to quote from Bygate when he is discussing how to learn spoken language. After he citing some traditional methods for learning spoken language, he says,

"Ten years later, during which time this approach to teaching oral skills had been widely adopted, David Wilkins pointed out there were some learning problems that exercises like these did not solve. An important one is that of ensuring a satisfactory transition from supervised learning in the classroom to real-life use of the skill. This transition is often called the "transfer of skills'." (1991, p. 6).

Here he mentions the 'transfer of skills' from classroom learning to real-life. This is really a widespread problem in China, where the English language learning environment is not sufficient enough. But we have tried to make more opportunities for students keep in frequent touch with English. It is very helpful to bring up something that attracts students' interests. The English corner is a very good example. English corner is a certain place for people to gather together with each other to talk in English language. In Jinan, the city where I live, we have an English corner in the central city park. Most of them are students and teachers and also some native speakers. They talk on various issues and exchange their ideas in English. English corner constitutes a kind of microcosmic English language environment.

As for the method of learning and teaching spoken English, the Audiolingual method is worth mentioning here,

"Audiolingual method, a very different approach, emphasizing the spoken language, became popular in the 1950s. 
This involved a systematic presentation of the structures of the L2, moving from the simple to the more complex, often in the form of drills which the students had to repeat. This approach, called the Audiolingual method, was strongly influenced by the belief that the fluent use of a language was essentially a set of 'habits' which could be developed with a lot of practice." (Yule, 1996, p. 193)

The audiolingual method emphasizes the learning of spoken language. It is disputable due to its own disadvantages. But I appreciate the idea of 'habits' mentioned here. Practice makes perfect. When the learner practices the spoken language more and more, a set of habits can be formed inside him/her, which would make him/her to produce spoken language in L2 from consciously to somewhat unconsciously and speak the L2 more naturally.

Besides the factors mentioned above, there is a major problem still exists for English language learners in speaking skills. As the civilization and society are advancing, the function of maintaining interpersonal relationship in spoken language is becoming more and more prominent.

“...in a reciprocal exchange, a speaker will often have to adjust his or her vocabulary and message to take the listener into account. The speaker also has to participate actively in the interlocutor's message — asking questions, reacting and so on. This is something which requires an ability to be flexible in communication, and a learner may need to be prepared for it." (Bygate, 1991, p. 8)

This means that even if you can pronounce the right sentence with proper intonation, it is still not enough. Perhaps there are quite a few words and sentence structures to express the same meaning. Which one should be employed for the best purpose of communication and smoothing the relationship at the same time? In order to communicate successfully, the learner must have mastered most of the language skills and have a considerable understanding of the certain culture where the L2 is spoken and then could he have the ability to handle variational situations freely. This is really a high demand for an L2 learning.

Another difficulty arises when we consider that English language varies from country to country and even from area to area. It is not so easy to say what is standard English. British English? American English? Canadian English? Australian English? Singapore English? And still many other kinds of English. They are all English but they are different in many ways, from lexical choosing to intonation employment. To deal with these variations in English language, we introduced more and more authentic materials to our English language learning class for students to listen to and have a general grasp about it. And students are encouraged to listen to BBC as well as Voice of America and try to imitate British English or American English.

Spoken language is flexible and open to change. It is not easy to get a good mastery of the spoken language in the L2. But it is possible to establish a good basis in pronunciation and the grammar of the target language. When it is possible to apply it to real life, the learner will make it soon. I myself am an example of this. My spoken English is not very good in China. When I first came to England, I really found listening and speaking difficult. But after 3 months stay, I feel it is much easier for me to communicate with others in various circumstances. The greatest difference from China is that I am in an English speaking environment here. From my own point of view, this circumstance is of vital importance for English language learners for speaking good English. That is the very reason why I came here to study and live for a year.

\section{How to Deal with Written Language in ENGLiSh LANGUAGE LEARNing AND TEACHING}

Yule points out that:

"When we consider the development of writing, we should bear in mind that a very large number of the languages found in the world today are used only in the spoken form. They do not have a written form. For those languages which do have writing systems, the development of writing, as we know it, is a relatively recent phenomenon. ...” (1996, p. 9).

Written language appeared much later than spoken language and initially it just wrote down what people spoke. But with the development of different special purposes of writing, written language developed its own style and own rules and became a highly-demanded skill of language. In a very long period, writing is always a symbol indicating person's educational level. In TOEFL and IELTS tests, the written module is usually considered to be the decisive module. Many universities or colleges' English proficiency entrance requirement is like this, IELTS overall band no less than ... with writing module no less than ...

In China, we always put attention on English writing. Unlike speaking skills, writing is much more constant and has relatively stable grammar to refer to. In this sense, learning to write in English is not so difficult as learning to speak in English. But learning to write proper English is a very hard work.

"An ability to speak well-fluently, persuasively, appropriately-is something that most of us would hope to achieve in our first language. it is also an objective for many learners of a foreign language, especially those who wish to do business internationally, or to study to travel in English speaking countries. An ability to write appropriately and effectively is, however, something which evades many of us, in our mother tongues or in any other languages we may wish to learn, and this in spite of the many years which are frequently devoted to the development of the skill." (Tribble, 1997 , p. 3)

Even in the case of first language acquisition, people need to learn writing in their mother tongue on purpose, usually in schools. It is no wonder that we consider writing a difficult skill to learn in the case of second language learning.

For writing, the learner should first have a good mastery of English vocabulary which would make it possible for him 
to choose the most appropriate words for his/her writing. Besides this, he/she is expected to be good at various sentences structures and have a relatively full knowledge of English grammar. At last, he/her should lay out a logical outline for his/her writing as a whole.

Here I would still like to recommend authentic materials for students to read. By 'authentic materials' here, I mean the materials written by native English-speaking authors. Read more and practice more would help the learner to write much more like native speakers.

Writing is indeed a big issue in language learning. It is not easy trying to cover all its aspects in this essay here. It is an advanced and important skill for a foreign language learner.

\section{CONCLUSION}

The function of language is to communicate with others to survive and to maintain certain interpersonal relationships. As two skills of language, speaking and writing have their own characteristics and they have fundamental differences in many respects. This requires different learning and teaching methods to deal with them respectively.

There are different examples regarding learning and teaching spoken language and written language. As an English teacher in China, how to apply both of them appropriately to the classroom is of vital importance. Language is a changeable system, especially the spoken language. It really seems impossible to work out a perfect plan of how to learn and teach spoken language and written language. What we can do is to do our best to improve the better methods and materials and map out different teaching plans for the various needs of English learners.

\section{REFERENCES}

[1] Brown, G \& Yule, G. (1983). Teaching the Spoken Language. Cambridge: Cambridge University Press.

[2] Bygate, M. (1991). Speaking. Walton Street, Oxford: Oxford University Press.

[3] Kuo, I-C. (2006). Addressing the Issue of Teaching English as a Lingua Franca. ELT Journal 60.3, 213-220.

[4] Tribble, C. (1997). Writing. Great Clarendon Street, Oxford: Oxford University Press.

[5] Yule, G. (1996). The Study of Language $2^{\text {nd }}$ ed. Trumpington Street, Cambridge: Cambridge University Press.

Bei Zhang was born in Yuncheng, China in 1976. She obtained her M.A. degree in Education from University of Bath, England in 2004. In 1998, she received B.A. degree in English from Shandong University.

She is currently a lecturer at the School of Foreign Studies of Shandong University of Finance and Economics, Jinan, China. 